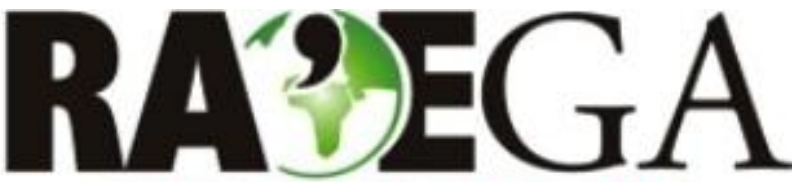

O ESPACYO GEOGRAFICO EM ANÁLISE

\title{
AS SUPERFÍCIES GEOMORFOLÓGICAS E A EVOLUÇÃO DO RELEVO BRASILEIRO: TRANSCURSO DAS IDEIASS E CORRESPONDÊNCIAS NO SUL DE MINAS GERAIS, SUDESTE DO BRASIL
}

\section{GEOMORPHOLOGICAL SURFACES AND THE EVOLUTION OF BRAZILIAN RELIEF: PASSING IDEAS AND CONNECTIONS IN SOUTHERN GENERAL MINES, SOUTHEAST BRAZIL}

\author{
Roberto Marques Neto \\ Professor da Universidade Federal de Juiz de Fora (UFJF) \\ Departamento de Geociências \\ Juiz de Fora, $M G$ \\ e-mail: roberto.marques@ufj.edu.br
}

Recebido em: 08/10/2013

Aceito em: 01/09/2014

\section{Resumo}

As discussões acerca das superfícies geomorfológicas não representam ponto de pleno consenso na cultura geomorfológica brasileira. Em função desse caráter, algumas ideias se coadunam ou se contrastam no que se refere à interpretação da gênese, evolução e período de elaboração das superfícies geomorfológicas consideradas para o território nacional. Em motivação dada pelo estado da arte referido, o presente artigo tem por objetivo colocar em diálogo a concepção dos principais autores que tiveram preocupação estabelecida nessa temática, procurando estabelecer correspondências no âmbito da evolução do relevo na bacia do Rio Verde, sul de Minas Gerais. A bacia de drenagem em questão perpassa terrenos da Serra da Mantiqueira, Planalto do Alto Rio Grande e Planalto de Varginha, possuindo uma série de patamares relacionados a diferentes controles tectônicos e litológicos. A diversidade morfológica existente na bacia do Rio Verde se transfigura em superfícies geomórficas de diferentes contextos genéticos e evolutivos, tendo sido identificadas superfícies de erosão propriamente ditas (Planalto de Cruzília-Minduri), superfícies estruturais, bem como superfícies dissecadas, tectonicamente deformadas e com aplainamentos localizados nos patamares de cimeira. Quanto à Superfície Sul-americana, ficou reconhecida uma heterogeneidade altimétrica vinculada a intensos basculamentos de blocos responsáveis pelo desnivelamento de níveis cronocorrelatos, mas que em alguns contextos apresentam coberturas de alteração preservada na forma de lateritas e bauxitas. 
AS SUPERFÍCIES GEOMORFOLÓGICAS E A EVOLUÇÃO DO RELEVO BRASILEIRO: TRANSCURSO DAS IDEIAS E CORRESPONDÊNCIAS NO SUL DE MINAS GERAIS, SUDESTE DO BRASIL)

Palavras-chave: Superfícies geomórficas, Superfície Sul-americana, Serra da Mantiqueira, Planalto do Alto Rio Grande.

\begin{abstract}
The debates on geomorphological surfaces do not represent a point of full consensus on brazilian geomorphological culture. For this feature, some ideas assemble or contrast regarding to the interpretation of the genesis, evolution and preparation period of geomorphological surfaces considered for the national territory. Motivated for the above-mentioned, this paper intend to dialogue with the conception of the main authors who have been preoccupied with this thematic, trying to establish correspondences under the relief development on the Rio Verde basin, south of Minas Gerais. The concerned drainage basin goes through the lands of Mantiqueira Mountain Range, Alto Rio Grande Plateau and Varginha Plateau, and has a series of levels related to different tectonic lithological controls. Morphological diversity in the Green River basin is transformed into geomorphic different genetic and evolutionary contexts surfaces, erosion surfaces themselves (Plateau Cruzília-Minduri), structural surfaces have been identified as well, tectonically deformed and dissected surfaces aplainaments located in the heights of the summit. As for the South American Surface, was recognized a linked to intense tilt blocks responsible for the uneven levels of chronocorrelates altimetry heterogeneity, but in some contexts include coverages change preserved in the form of laterites and bauxites.
\end{abstract}

Keywords: Geomorphical surfaces, Sul-americana Surface, Mantiqueira Moutain Range, Alto Rio Grande Plateau.

\title{
INTRODUÇÃO
}

Inequivocamente as discussões acerca das superfícies geomorfológicas estão entre os temas menos consensuais na cultura geomorfológica brasileira. A cronologia do pensamento é marcada por elaborações de modelos explicativos da evolução do relevo brasileiro por meio da abordagem nos termos das superfícies de aplainamento, conforme revisão elaborada por Silva (2009), que elucida a confusão terminológica existente entre as superfícies erosivas, associadas a processos de denudação em diferentes litologias levando a formação de níveis altimétricos diferenciados, e as chamadas superfícies estruturais, que correspondem a níveis mantidos numa mesma faixa altimétrica em função da própria estrutura geológica. Tais terminologias evocadas para a explicação da gênese de diferentes níveis altimétricos do relevo vêm sendo unificadas pelo emprego do termo superfície geomorfológica.

Daniels e Hammer (1992) reconhecem a existência de superfícies construtivas (acumulativas) formadas por processos de deposição sedimentar, e de 
superfícies erosivas, estas últimas formadas por processos erosivos eólicos, de movimentos de massa ou pela ação da água, frisando que a maioria das superfícies de erosão apresentam elementos deposicionais em declives de até $20 \%$, sendo, entretanto, os sedimentos associados (e não o declive da encosta) que distinguem as superfícies erosivas das deposicionais. A tal respeito, os autores fazem a seguinte colocação:

A geomorphic surface can be level planar, or steeply sloping and ranging from planar through concave and convex or any combination of those shapes. A geomorphic surface is an area of land that has a development history related in space and time. A geomorphic surface is either constructional or erosional or both. All erosional surfaces during their formation grade to a constructional surface. (DANIELS e HAMMER, op cit, p. 136).

Nessa concepção as superfícies geomórficas podem ser erosivas ou acumulativas, ou mesmo manter as duas origens. Ocorrem tanto em litologias diversas como em mesmo domínio litológico, e admitem terem sido elaboradas em largo tempo geológico ou em amplitudes temporais mais curtas.

Consideramos na presente comunicação superfícies geomorfológicas de caráter erosivo - paleosuperfícies ou em vias de elaboração - e acumulativo, representadas por superfícies elaboradas a partir de processos predominantemente deposicionais, além das superfícies estruturais mantidas em condição de patamares sobrelevados por fatores de ordem tectônica (epirogênese diferencial) ou litológica (resistência da rocha ao ataque químico).

As superfícies de aplainamento configuram áreas de estruturas diversas que foram aplainadas ou cortadas indiferentemente pela erosão, o que repercute em uma forma topográfica discordante da estrutura, localizada acima do nível de base regional e modelada por processos de denudação subaérea, associados ou não a processos de acumulação (PINTO, 1988). Para Geyl (1961), seria uma área relativamente plana formada por processos de erosão normal durante um período de estabilidade do nível de base.

Small (1986) ressalta a importância do controle imposto pelos níveis de base locais na elaboração de uma superfície de aplainamento, cujo reconhecimento é 
feito pela análise destes níveis, responsáveis pela preservação ou dissecação e consequente destruição da superfície.

Ciente das problemáticas que avultam quando a presente discussão é trazida à baila, o presente artigo objetiva contribuir com o entendimento do papel das superfícies geomorfológicas na evolução do relevo brasileiro através de uma revisão e discussão comparada das ideias dos principais autores que se dedicaram ao tema. Em seguida, procura-se estabelecer relações entre as principais superfícies geomorfológicas citadas na literatura (enfaticamente a Superfície Sul-americana) e seu posicionamento e significado geomorfológico na região sul de Minas Gerais, enfaticamente na bacia hidrográfica do Rio Verde, cuja área expressiva $\left(6891,4 \mathrm{~km}^{2}\right)$ distribuída em terrenos da Serra da Mantiqueira, do Planalto do Alto Rio Grande e do Planalto de Varginha, confere a essa bacia forte representatividade do quadro geomorfológico regional.

\section{MATERIAIS E MÉTODOS}

Os procedimentos metodológicos acionados para a feitura da presente pesquisa congregaram, fundamentalmente, estudos bibliográficos, cartográficos e trabalhos de campo.

Foi empreendida uma análise histórico-comparativa dos principais referenciais bibliográficos que trataram da temática colocada em discussão, encerrando-se as bibliografias consideradas fundamentais, e que aparecem citadas ao longo do texto. Também foram utilizados referenciais acessórios que, embora não sejam os mais recorrentemente citados quando se volta o foco para este assunto, representam estudos importantes levados a efeito para áreas específicas do território brasileiro.

Pautou-se na representação cartográfica dos topos sobre as folhas topográficas em escala de 1/250.000, especificamente as seguintes: Barbacena, SF23-X-C (IBGE, 1979), Varginha, SF-23-V-D (IBGE, 1979), Volta Redonda, SF-23-Z-A (IBGE, 1976) e Guaratinguetá, SF-23-Y-B (IBGE, 1985). Subsidiariamente foi adotado o procedimento de análise de frequência e área de topos (CLARKE, 1966), também empreendido por Varajão (1991) e Magalhães Jr e Trindade (2004). A partir deste procedimento foi possível identificar a distribuição regional das superfícies 
preservadas e o estabelecimento de correlações entre os níveis altimétricos, a tectônica, a natureza das litologias envolvidas e a presença de algumas coberturas de alteração laterizadas ainda preservadas no perfil de intemperismo. O processo de delimitação seguiu as orientações de Barbosa (1980), definindo-se o traçado sobre as curvas de nível fechadas marcadoras das rupturas com as encostas dissecadas. Posteriormente os topos foram digitalizados em software Auto Cad, ambiente digital onde o documento cartográfico foi gerado.

A altimetria foi relacionada à tectônica a fim de averiguar os efeitos diastróficos atuando no desnivelamento de superfícies correlatas mediante sobreposição com os lineamentos estruturais representativos de traços retilíneos do relevo, muitas vezes vinculados à zonas de cisalhamento tectonicamente ativas; a comparação com o mapa geológico, por sua vez, foi procedimento de averiguação de superfícies estruturais dadas por fatores de ordem litológica. A extração dos lineamentos se deu segundo as orientações de Liu (1984) aplicada sobre imagens de radar SRTM (Shuttle Radar Topography Mission), também aproveitadas para compartimentação geomorfológica prévia, nos moldes dos procedimentos executados por Valadão (1998) a partir de imagens de radar de visada lateral, possibilitando a identificação dos diferentes níveis planálticos a partir dos elementos texturais.

As campanhas de campo foram dedicadas para averiguação de restritas ocorrências de bauxitas e lateritas autóctones ou retrabalhadas. Em maior medida também se voltaram para identificação de evidências morfológicas da paleotectônica responsável pela reativação das falhas que geraram a Serra da Mantiqueira, bem como da atividade neotectônica que vem deformando as superfícies preexistentes e engendrando desnivelamento altimétrico entre superfícies de mesma geração a partir da reativação de falhas antigas e nucleação de novas falhas.

\section{RESULTADOS E DISCUSSÃO \\ O ESTUDO DAS SUPERFÍCIES GEOMORFOLÓGICAS NO BRASIL}

Entre os diversos autores que se dedicaram aos estudos das superfícies de aplainamento e dos níveis de erosão embutidos destacamos os trabalhos de: De Martonne (1943), Freitas (1951), King (1956, 1962, 1976), Ab'Sáber (1960, 1969, 
2007), Ab'Sáber e Bigarella (1961), Almeida (1964), Bigarella e Mousinho (1965), Braun (1971), Ranzani, et al. (1972), Barbosa (1976; 1980), Pinto (1986), Varajão (1991), Valadão (1998; 2009), Almeida e Carneiro (1998), Peuvast e Sales (2002), Marques Neto (2012).

Os primeiros estudos mais concisos sobre as superfícies de aplainamento em território brasileiro foram levados a efeito por De Martonne (1943). Bigarella (2003) cede mérito ao autor argumentando que, anteriormente aos seus estudos, as superfícies aplainadas registradas no Brasil eram interpretadas como resultado de processos de peneplanização que atuaram em largo tempo geológico, ao gosto da geomorfologia davisiana. A essa ordem de interpretação se coaduna a ideia de peneplano extensivo de Washburne (1930) concebida para a Depressão Periférica Paulista, ou ainda os estudos de Preston James (1933) para o sudeste brasileiro.

Os estudos desempenhados por De Martonne (1943) deram lugar a uma concepção de três ciclos responsáveis pela evolução de três grandes níveis de aplainamento, a saber: Superfície dos Campos (Cretáceo Médio), Superfície Paleogênica (Paleógeno) e Superfície Neogênica (Neógeno). O geógrafo francês também reconheceu uma superfície nas proximidades de Itu (SP), de idade prépermiana, posteriormente exumada. Almeida (1964) denomina-a de Superfície Itapeva, reconhecendo que a mesma serviu de base para o assentamento dos sedimentos da Formação Furnas, de idade devoniana.

Nos estudos de Freitas (1951), o fator tectônico foi considerado como o principal elemento responsável pela geração de superfícies de erosão. De interesse para a área de estudo, o autor esquematiza sua concepção da seguinte forma: 1) Peneplano de nível A (1800-2000 metros), interpretado como ruptura tectônica de uma antiga superfície de erosão, materializando blocos mais senis em contraste a jovialidade das frentes escarpadas, formando cimeiras aplainadas pontuadas por charcos e banhados; Peneplano de nível B (1200-1400 metros), de caráter extenso e descontínuo, foi interpretado como base para a sobrelevação do nível $A$, que teria se dado por interferência tectônica a partir deste nível atualmente mais rebaixado. Em relativa aproximação, tais peneplanos correspondem à Superfície dos Campos e Paleogênica de Emmanuel De Martonne. Sem especulações contundentes a respeito da cronologia dos níveis supramencionados, o autor dá ênfase às ações 
tectônicas para explicar a evolução morfológica da Serra da Mantiqueira e recorre com certa frequência às referências altimétricas na interpretação das superfícies geomórficas.

Posteriormente a estes ensaios, sobrevieram os estudos realizados por Lester C. King (KING, 1956, 1962), que na época levou à concepção de uma sequência de ciclos erosivos responsáveis pelo aplainamento de suas respectivas superfícies geomórficas, a saber: Superfície fóssil carbonífero-devoniana; superfície desértica (Triássico); Ciclo Gondwana (Cretáceo Médio), Ciclo Pós-Gondwana (Cretáceo Superior), Ciclo Sul-americano (Paleógeno), Ciclo Velhas (Pliopleistoceno) e Ciclo Paraguaçu (Quaternário). As duas fases mais antigas foram eminentemente agradacionais, e teriam se dado em uma massa litosférica em subsidência. As demais são predominantemente de denudação, e suas elaborações estariam ligadas à elevação da massa continental.

Entre os ciclos de erosão concebidos por King, aquele mais recorrentemente mencionado, e objeto de relações mais diretas, se refere ao que engendrou a Superfície Sul-americana, de idade paleogênica. Sua esculturação teria se dado em longo lapso temporal, o que fez com que atingisse grande uniformidade de aplainamento. Para o autor (KING, 1956, p. 167) "esta superfície aparece frequentemente como chapadas que se elevam sobre sistemas de vales ou planícies onduladas, produtos da ação de ciclos posteriores". Prosseguindo (op cit. p 168), "os remanescentes aplainados desta superfície ainda a individualizam apesar da dissecação subsequente, como a superfície fundamental na qual a topografia moderna foi esculpida".

A Superfície Velhas, ainda segundo a concepção de King, teria se formado a partir da denudação da Superfície Sul-americana, e se apresenta na forma de relevo ondulado produto de ampla pedimentação. Encontra-se dissecada pelo ciclo mais recente, designado Paraguaçu, responsável pela abertura de gargantas e vales em nova frente erosiva a dissecar a superfície anterior. Este ciclo não teria ainda atingido amplo aplainamento, estando restrito a proximidades da costa atlântica ao longo dos vales dos principais rios.

O estudo das superfícies de erosão desde o início é marcado por uma notória discordância entre os autores no que concerne a nomenclatura, período e 
tempo de duração dos ciclos denudacionais que agrediram as paisagens brasileiras durante o Cenozóico. Entretanto, no afã de compreender a evolução do relevo brasileiro, certa convergência de ideias se cristalizou na interpretação da superfície Sul-americana, identificada em uma série de compartimentos de cimeira distribuídos pelo território nacional.

É reconhecido para a Superfície Sul-americana um longo período de aplainamento que se estendeu por todo o Paleógeno. Braun (1971) chega ao extremo de considerar que todo o relevo brasileiro atual foi esculpido a partir da referida superfície. Constitui uma superfície de erosão bastante ampla, ocupando as chapadas ao sul da Serra do Espinhaço e o setor meridional do estado de Minas Gerais.

Contemporaneamente aos trabalhos de L. King, o geógrafo brasileiro Aziz N. Ab'Sáber defendeu sua tese de doutorado frente a Universidade de São Paulo, publicada mais tarde na forma de livro (AB'SÁBER, 2007), reconhecendo no sítio urbano de São Paulo a presença de uma superfície mais antiga entre 1100 e 1300 metros a qual designou como Superfície das Cristas Médias, na qual se encontram embutidos níveis mais recentes designados como Superfície Itapecerica-Cotia (900 a 950 metros) e Superfície de São Paulo (800-850 metros). Tais superfícies, respectivamente datadas do Cretáceo, Paleógeno e Plio-pleistoceno, foram interpretadas pelo autor como testemunhos de relevos policíclicos.

Aos patamares mais elevados do estado de São Paulo e sul de Minas Gerais, preservados, sobretudo, em litologias quartzíticas e gnaisse-granitos quartzosos, Almeida (1964) chamou de Superfície do Japi, que corresponde à Superfície Sul-americana de L. King ou das cristas médias de A. Ab'Sáber, propondo que este extenso nível de aplainamento e os patamares mais elevados da antéclise da Mantiqueira (Superfície dos Campos, de Emmanuel De Martonne) correspondem à mesma superfície geomórfica. Reconheceu o aplainamento Japi nos topos das serras e residuais esculpidos nos planaltos cristalinos paulistas, Serra do Mar, Planalto de Poços de Caldas, Serra da Mantiqueira e centro-sul de Minas Gerais, de onde se prolonga em alinhamentos serranos que adentram Goiás na região de Piracamjuba e Caldas Novas até as partes centrais e norte do estado, pela Serra Negra e Chapada dos Veadeiros. Também se encontra preservada em morfologia 
tabuliforme nos divisores das bacias dos rios São Francisco e Paranaíba, no oeste mineiro.

Reiterando tais concepções, Almeida e Carneiro (1998) asseveram que os indícios da Superfície Sul-americana aparecem em grandes extensões do sudeste brasileiro, ora nivelando cumeadas de sistemas orográficos de destaque como as serras do Mar e Mantiqueira, ora ocorrendo localmente no topo de planaltos elevados, nivelando as mais variadas estruturas, inclusive intrusões alcalinas senonianas do oeste de Minas Gerais e sudeste de Goiás.

Sobre a Serra do Mar, em específico a Serra dos Órgãos (RJ), Hartwig (2006) declara concordância com os autores clássicos mencionados acerca da subsistência de uma superfície de erosão correspondente a Sul-americana.

Conforme as elucidações de Valadão (2009), a elaboração da Superfície Sul-americana remonta ao processo de rifteamento da placa Afro-brasileira, que, ainda no estágio sin-rifte, a ruptura crustal e soerguimento geraram imponentes escarpas de falha no Brasil Oriental, organizando uma rede hidrográfica menos agressiva voltada para o interior e separada por interflúvios escarpados que foram gerados de outro sistema hidrográfico, composto por bacias de drenagens mais agressivas voltadas para o oceano em formação.

Hasui (1990) também reconhece que a Superfície Sul-americana aplainou enorme extensão do Brasil Oriental, sendo tectonicamente alçada até as altitudes atuais (em torno de 1100 metros) no Brasil Centro-Oriental, alçamento este que viabilizou a esculturação do relevo atual através de pulsos com assinaturas em superfícies de erosão mais recentes.

Para o Brasil Central, Pinto (1986) identifica a Superfície Sul-americana como residual de aplainamento na região da Chapada dos Veadeiros, onde se mantém em altitudes superiores a 1400 metros nos patamares interfluviais marcadas por escalonamento topográfico que Braun (1971) chegou a interpretar como inselbergues subsistentes ao relevo pós-gondwano. Na interpretação de Pinto (op cit.), o modelo da etchplanação é que explica a gênese dos patamares residuais aplainados da chapada revestidos por Latossolos e laterita, processos estes que incidiram sobre uma superfície de idade cretácea em condições de clima tropical ao longo do Cenozoico, privilegiando o papel do intemperismo químico e distinguindo 
residuais cretáceos mais elevados de superfícies cenozoicas, além de um pediplano plio-pleistoceno. Paisani et al. (2008) também advogam a favor da importância dos processos de etchplanação na elaboração de superfícies de aplainamento em complemento aos modelos clássicos calcados na pedimentação.

Estudos nessa linha dedicados ao Brasil Central também foram apresentados por Nascimento (1992), que reconhece a prevalência da Superfície Sul-americana nos topos aplainados das mesetas do Planalto Central Goiano, destacadamente na subunidade do Planalto do Distrito Federal, onde aparece na forma de interflúvios levemente dissecados modelados predominantemente sobre quartzitos interestraficados com metasiltitos, filitos e argilitos protegidos por coberturas detrítico-lateríticas. A autora reconhece a ocorrência de desgaste mecânico por processo de pediplanação em clima semiárido na geração do relevo intermontano que caracteriza as extensas superfícies pedimentares do Planalto Central. Na Depressão do Araguaia aparece na forma de alinhamentos dissimétricos e hog backs residuais encravados em extensas superfícies rebaixadas.

Motta et al. (2002) também reconhecem a ocorrência do ciclo Sul-americano no Planalto Central Brasileiro, correspondendo aos topos de mesetas revestidos por LATOSSOLOS e capeados por canga laterítica, aos quais denominaram de primeira superfície. Ao que chamaram de segunda superfície corresponde a um plano inclinado que conecta a borda da superfície anterior aos fundos de vale, sugerindo associação com a Superfície Velhas. Uma terceira superfície reserva referência a áreas de dissecação mais recente, sem correlações diretas com as nomenclaturas recorrentes. Para estes autores a superfície geomórfica de referência também é a Sul-americana, com aplainamento completado na parte média do Cenozoico sucedido por dissecação da paisagem e inversão do relevo que realçou as chapadas com topos preservados pela presença de crostas petroplínticas.

No nordeste brasileiro, Barbosa (1976) correlacionou para o semiárido baiano a Superfície Sul-americana ao que designou como Superfície dos Geraizinhos, frisando que na região não há relevos aplainados mais antigos. É representado pelos remanescentes dobrados, geralmente balizados em quartzitos, tal como o geossinclíneo do Espinhaço, chamando a atenção para a possível relação dessas superfícies mais altas a um comportamento estrutural. 
AS SUPERFÍCIES GEOMORFOLÓGICAS E A EVOLUÇÃO DO RELEVO BRASILEIRO: TRANSCURSO DAS IDEIAS E CORRESPONDÊNCIAS NO SUL DE MINAS GERAIS, SUDESTE DO BRASIL)

Na região Norte, Costa (1991) reconheceu idade de formação de lateritos maturos entre o Eoceno e Oligoceno, com retrabalhamento posterior no Mioceno e Pleistoceno, correlacionando-os com o estabelecimento da Superfície Sulamericana.

A Superfície Sul-americana também vem sendo correlacionada ao topo das cuestas arenítico-basálticas (PENTEADO, 1968), que no estado de São Paulo estabelecem contato erosivo com a Depressão Periférica Paulista. No Mato Grosso do Sul tais feições ocorrem em caráter mais festonado e residual perfazendo a extremidade ocidental da Bacia Sedimentar do Paraná nos limites com a planície do Pantanal, dada pela Serra de Maracaju, consideravelmente nivelada e aplainada em suas cimeiras, em condição bastante residual.

Também na região das cuestas, Ladeira e Santos (2005) propuseram um modelo evolutivo regional do relevo (Serra de Itaqueri, estado de São Paulo) com base na análise de paleossolos e perfis de alteração (ferricretes, silcretes), reconhecendo uma superfície mais antiga que trunca as formações Botucatu e Serra Geral. A cronologia de sua elaboração foi inferida entre o Cretáceo Médio e Superior e início do Paleógeno.

A elaboração da Superfície Sul-americana remonta ao Mesozóico a partir da ruptura das placas Sul-americana e Africana, se desenvolvendo até o Mioceno Médio, quando teve início a sedimentação do Grupo Barreiras, perfazendo um tempo de elaboração em torno de $100 \mathrm{Ma}$ (BIGARELLA, 2003). A partir da reativação intraplaca do Cretáceo Superior, responsável pelo remodelamento das bacias marginais e pelo arranjo da rede hidrográfica da fachada Atlântica, a Superfície Sul-americana teria alcançado condições de relevo aplainado na passagem para o Cenozoico (VALADÃO, 1998). Após ter adquirido sua configuração final na transição Cretáceo-Paleógeno, a Superfície Sul-americana teve seu modelado retrabalhado entre o Paleoceno e o Mioceno Inferior, num intervalo superior a $40 \mathrm{Ma}$ (BIGARELLA, 2003).

Ao longo do Cenozóico a Superfície Sul-americana foi deformada por flexuras e falhamentos, erguendo-se gradualmente até altitudes superiores a 2000 metros na Mantiqueira, conforme já discutido por Almeida (1964). Durante sua deformação, o Planalto Atlântico foi exaustivamente desnivelado por falhas, 
desenvolvendo semigrábens com inclinação para NNW e orientados segundo direções ENE das falhas pré-cambrianas reativadas, originando um sistema de bacias tafrogênicas (Taubaté, Resende, Volta Redonda, Guanabara) paralelo a Serra do Mar (ALMEIDA e CARNEIRO, 1998).

O soerguimento miocênico implicou na elevação de grande parte do território brasileiro, com reativações intraplaca generalizadas, o que repercutiu numa significativa denudação continental responsável pela interrupção da elaboração da Superfície Sul-americana. Tal soerguimento modificou o nível de base no interior do continente e da fachada atlântica, rejuvenescendo a rede hidrográfica e iniciando a elaboração, até o Plioceno Superior, da chamada Superfície Sulamericana I, num lapso temporal que não ultrapassa 8 Ma (VALADÃO, 1998). A partir de um novo soerguimento ocorrido no Plioceno Superior, o autor contextualiza a elaboração da Superfície Sul-americana II, que ocupa o piso das depressões interiores e sublitorâneas, correspondendo, grosso modo, à Superfície Sertaneja proposta por Ab'Sáber (1969).

As denominações Superfície Sul-americana I e Superfície Sul-americana II partem do pressuposto de que as superfícies que sucederam a Superfície Sulamericana tiveram (e estão tendo) sua elaboração processada a partir do desgaste daquela extensa superfície. Correspondem, grosso modo, às superfícies Velhas e Paraguassu de King (1956).

A diversidade tectono-estrutural caracterizada por epirogênese desigual vigente em uma série de contextos geomorfológicos brasileiros e os conhecidos e ainda pouco investigados processos de desgaste geoquímico do modelado se fazem elementos complicadores no estudo de superfícies geomórficas, dificultando as interpretações e impondo cautela às correlações entre um nível topográfico dado e uma superfície. Com essa óptica foram feitas as considerações acerca das superfícies existentes na bacia do Rio Verde.

\section{SUPERFÍCIES GEOMORFOLÓGICAS NA BACIA DO RIO VERDE}

Reconhecidamente, a bacia do Rio Verde é depositária de uma série de níveis morfológicos, em grande medida dados por fatores tectônicos. Tais níveis são relacionáveis a uma série de menções na literatura. O bloco mais elevado 
corresponde aos maciços alcalinos de Itatiaia e Passa Quatro, terreno de afinidade morfológica com a Superfície dos Campos proposta por De Martonne (1943), ou Sulamericana/Japi (KING, 1956), (ALMEIDA, 1964), respectivamente. Gerado por intrusão alcalina ocorrida no final do Cretáceo e início do Paleoceno, tais blocos nivelam superfícies estruturais preservadas pela maior resistência ao intemperismo das rochas mesocráticas que conformam o compartimento.

Zalan e Oliveira (2005) correlacionam as altitudes elevadas acima de 2000 metros no sudeste brasileiro (stocks alcalinos de Itatiaia e Passa Quatro, serras da Bocaina e dos Órgãos, Planalto de Campos do Jordão) à Superfície do Japi, que também apareceria em extensos cumes planos a 1000-1300 metros na Serra do Mar, bem como em alinhamentos serranos rebaixados até 700 metros, cujo entalhamento/aplainamento seria de idade neocretácea. Os autores tomam por hipótese que as maiores altitudes se aproximam mais da posição original dessa superfície no final do Cretáceo. Para Hasui (2010), o desenvolvimento da Superfície Sul-americana a partir do final dos tempos cretáceos teria se dado em função de um período de estabilidade tectônica, que marcou a tônica da evolução morfológica até o Eoceno-Mioceno, quando novo soerguimento afetou contundentemente a fachada atlântica brasileira.

A raridade de materiais preservados e datáveis do Cretáceo ou mesmo do Paleoceno nos altos cumes da Mantiqueira, no entanto, dificulta uma aferição precisa da idade dos patamares de cimeira e o estabelecimento de uma cronologia da denudação em caráter plenamente sistemático. A gênese tectônica da Serra da Mantiqueira e os processos de soerguimento e efeitos deformacionais pós-cretáceos não permitiram a esculturação de uma superfície homogeneamente aplainada, mas sim uma série de níveis topográficos dados pela ação erosiva, pela estrutura e por efeitos de natureza tectônica.

No entanto, em Passa Quatro foram encontradas bauxitas alumínicas geneticamente vinculadas ao maciço alcalino, do qual configuram depósito correlativo. Tais materiais constituem depósito de talude (bauxitas alóctones) sobrejacente às rochas metamórficas pré-cambrianas, caracterizados por endurecimento e formando crostas extremamente enrijecidas cobertas por NEOSSOLO LITÓLICO (figura 1A). Thomas (1994) esclarece que a formação e 
destruição de perfis ferruginosos ou bauxíticos registram importantes episódios da evolução da paisagem, determinando diferentes níveis geomorfológicos nas regiões tropicais úmidas. Depósitos similares de mesmo vínculo genético em outras vertentes do maciço alcalino foram datados por Sígolo (1997) entre o Eoceno e Oligoceno e, necessariamente, são posteriores às intrusões alcalinas, apontando a idade mencionada como a mais provável para os depósitos de Passa Quatro, que devem ter se depositado depois do Cretáceo/Paleoceno, ao encerramento do magmatismo alcalino em contexto. Tais processos supérgenos foram bastante comuns no Eoceno-Oligoceno, época de clima bastante quente e úmido que favoreceu a formação ampla de perfis bauxíticos e lateríticos, alguns ainda preservados.

Além das bauxitas de Passa Quatro também foram aferidas formações lateríticas em São Thomé das Letras, no Planalto do Alto Rio Grande. Esse capeamento foi encontrado em relevo de morro de encostas suavizadas que dá aporte à pedogênese latossólica e de ARGISSOLOS, estando posicionado em topo aplainado nivelado em faixa ligeiramente acima de 1000 metros de altitude e sem afinidade morfológica com a Superfície Sul-americana/Japi. O pacote intemperizado subjacente constitui material argiloso bastante ferruginizado coroado pelo resistente capeamento laterítico, que segrega uma bancada mais endurecida no topo do perfil (figura 1B).

Se a idade relativa desses materiais estiver entre o Eoceno e o Oligoceno, de acordo com o que vem sendo constatado em áreas cristalinas do sudeste brasileiro, o aplainamento dado nas áreas adjacentes às cristas quartzíticas remete aos tempos mais inferiores do Cenozoico, com perfis preservados nos topos e com prováveis interferências tectônicas. Ladeira e Santos (2005) enfatizam que os perfis lateríticos são importantes indicadores de superfícies geomórficas, uma vez que só evoluem mediante relativa estabilidade tectônica e climática e durante largo tempo cronológico.

Em segmento do interflúvio que separa as bacias dos rios Verde e Grande no município de Cruzília, foram encontradas crostas superficiais lateríticas compreendidas entre 1140 e 1150 metros de altitude, formatando-se uma faixa divisória distintamente aplainada e nivelada que adentra a bacia do Rio Grande em 
suave interflúvio revestido por coberturas latolizadas de textura argilosa. Sobre os materiais laterizados jazem cascalheiras formadas por fragmentos de tamanho variado de geometria predominantemente angular a subangular, sugerindo que 0 retrabalhamento não tenha sido muito intenso. Em termos de materiais, tem-se o predomínio do quartzo.

Outros autores também encontraram formações bauxíticas e lateríticas em outras regiões do Brasil Sudeste e correlacionaram sua ocorrência com a Superfície Sul-americana (VALENTON e MELFI, 1988), (GONTIJO, 2002), (ROMANA e CASTAÑEDA, 2006).

As formações lateríticas e depósitos bauxíticos são assim encontrados tanto na Serra da Mantiqueira como do Planalto do Alto Rio Grande. Do ponto de vista cronológico, tais evidências tentariam a uma correlação com a Superfície Sulamericana (ou do Japi). Como tais depósitos não apresentam maior continuidade e o soerguimento diferencial de blocos é marcante, evitaremos as correlações taxativas e a obrigatoriedade em optar por uma nomenclatura existente. No entanto, essas constatações são congruentes às concepções de King no sentido de apontar para uma provável fase de elaboração mais agressiva de uma superfície geomorfológica após o soerguimento que gerou a Serra da Mantiqueira, assinalando se tratar de um período fundamental para o entendimento da evolução regional do relevo. É bem verdade que o soerguimento tende a erodir as coberturas de alteração e escamotear os registros, mas, no entanto, algumas litologias, especialmente as rochas alcalinas, são bastante susceptíveis aos processos de bauxitização.

É latente a condição de cimeira do principal alinhamento subnivelado da Serra da Mantiqueira. Tal alinhamento tem extremidade nordeste na Serra do Papagaio a partir de onde se projeta em superfície estrutural que, pelo sul estabelece contato tectônico com o maciço alcalino de Itatiaia formando um contraforte contínuo (figura 1C).

Para o interior, ramificações geradas por deslocamentos para oeste assumem a condição de alinhamentos de topos aplainados, a exemplo da Serra da Chapada, um proeminente bloco falhado que se conecta bruscamente em ruptura negativa de declive com os patamares mais rebaixados, marcando os limites interioranos da crista principal da Mantiqueira (figura 1D). O que se constata é uma 
AS SUPERFÍCIES GEOMORFOLÓGICAS E A EVOLUÇÃO DO RELEVO BRASILEIRO: TRANSCURSO DAS IDEIAS E CORRESPONDÊNCIAS NO SUL DE MINAS GERAIS, SUDESTE DO BRASIL)

superfície tectonicamente sobrelevada cuja preservação também é marcada por uma diminuição na densidade de drenagem nesse compartimento local, o que teria sido favorável também para sua preservação à medida que foi poupado da frente erosiva remontante. Dessa forma, embora impere a dissecação e a epirogênese diferencial a impedirem um aplainamento uniforme, verifica-se aplainamentos localizados e de extensões desiguais nos níveis de cimeira, reconhecidos pelo padrão textural mais fino e homogêneo das imagens de radar.

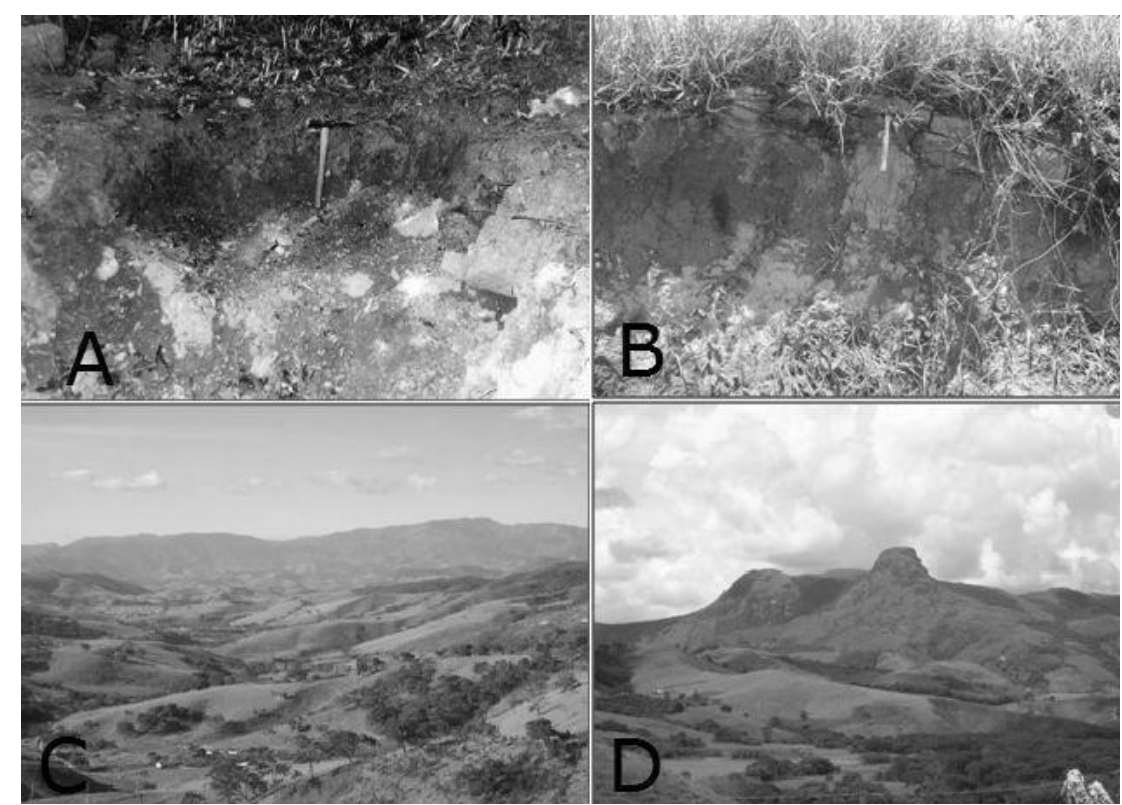

Figura 1. Depósitos bauxíticos em Passa Quatro $(A)$; Perfil laterítico em São Thomé das Letras (B); Patamar de cimeira da Serra da Mantiqueira representativo das maiores elevações da Superfície do Japi na região, (Passa Quatro) (C); Pico do Chapéu, limite interiorano da crista principal da Mantiqueira em ruptura de declive com os terrenos rebaixados adjacentes (Baependi).

Propõem-se como coerente considerar a Superfície dos Campos e Sulamericana ou do Japi como uma única superfície geomorfológica, subnivelada na Serra da Mantiqueira e Planalto do Alto Rio Grande em função da heterogeneidade epirogenética distribuída entre as zonas de cisalhamento ocorrentes na área. A correspondência das duas superfícies acima arroladas é antiga, e já fora insinuada por autores como Almeida (1951) e Freitas (1951). Em consonância a Almeida (1964), a Superfície dos Campos corresponderia à Superfície do Japi ou das cristas médias deformada e soerguida, apontando diferentes eventos tectônicos e denudacionais pós-cretáceos, a semelhança do que Hiruma (2007) constatou para a Serra da Bocaina, em região limítrofe entre os estados de São Paulo e Rio de 
Janeiro. Também para a região da Bocaina, Gontijo et al. (2002) assumiram adesão à interpretação de um arqueamento da Superfície Sul-americana ou do Japi que teria se dado antes da deposição dos sedimentos da Formação Rezende, de idade cenozoica, sugerindo ainda que a Superfície Velhas corresponderia, nessa área, a um retrabalhamento da superfície geomórfica precedente, abatida ou soerguida tectonicamente em algumas dezenas de metros e atualmente identificada pelos topos de compartimentos de colinas do embasamento. Riccomini et al. (2004) reconhecem que a Superfície do Japi encontra-se, nos terrenos do Rift Continental do Sudeste do Brasil, em faixas altimétricas de 1200 metros quando não deformadas e acima de 2000 metros quando tectonicamente soerguida.

$\mathrm{Na}$ parte média/baixa da bacia do Rio Verde é outra superfície geomorfológica que se configura, mais nivelada em morros e pequenas colinas que imbricam em direção a represa de Furnas. Indubitavelmente trata-se de uma superfície mais recente que mantém maior afinidade com a Superfície Velhas (KING, 1956), cuja elaboração remete fundamentalmente ao Quaternário, ainda que os materiais superficiais possam por vezes apresentar idade mais antiga que pode remeter a tempos mais afastados do Neógeno.

Tais sistemas de relevo ondulado são secionados por cristas quartzíticas de orientação NE-SW que se estendem de São Thomé das Letras/Cruzília a Lambari. Constituem falhas de empurrão que impõem anomalias positivas dadas pela maior resistência do quartzito ao intemperismo, configurando autênticas superfícies estruturais correspondentes a eixos de soerguimento preferencial nos últimos controles setentrionais do cinturão de cisalhamento de Ouro Fino passando para os domínios da Zona de Cisalhamento de Lambari. A ausência de coberturas de alteração datáveis impede o estabelecimento de uma idade absoluta para estas superfícies, mas certamente se encontram preservadas sob a égide de um componente estrutural representado pelo quartzito.

As serras quartzíticas na bacia do Rio Verde, produto de dobramentos e falhas de empurrão (regime dúctil/rúptil), sucedem-se em cristas e vales conforme a resistência desigual das rochas. Nesse caso, vales escavados em micaxistos confinam-se estruturalmente entre as serras de São Tomé e do CantagaloSobradinho, ambas dissecadas por drenagem ressequente que desce pelo front 
escarpado voltado para leste e por rios cataclinais de reverso na vertente oeste. Coletores regionais importantes, contundentemente o próprio Rio Verde, festonam as cristas aproveitando-se de linhas de fraqueza.

Os alinhamentos quartzíticos apresentam suave mergulho para NW da ordem de $12^{\circ}$ em média. Embora o paralelismo das camadas metassedimentares não seja plenamente plano, os topos dessas serras são relativamente preservados. No entanto, a resistência do quartzito ao intemperismo químico não dá margem a formação de perfis de alteração espessos. Mesmo na Serra de Carrancas (bacia do Rio Grande), que são correlatas às cristas quartzíticas da bacia do Rio Verde em gênese e idade, as extensas cimeiras aplainadas são desprovidas de coberturas superficiais espessas, ocorrendo apenas NEOSSOLOS acentuadamente distróficos e arenosos e alguns materiais com horizonte $B$ incipiente.

Na região de São Thomé das Letras, Cruzília, Conceição do Rio Verde e Lambari, os topos e altas encostas das cristas quartzíticas que foram preservados da dissecação fluvial, identificados pelo fechamento das curvas de nível que separam as áreas da paisagem que não foram atacadas pela drenagem, conformam uma área de 19492,5 $\mathrm{m}^{2}$ distribuída em pelas serras de São Tomé, Cantagalo e Sobradinho em alinhamentos contínuos ou em patamares disjuntos.

A interpretação da paisagem revela, no entanto, um maior rebaixamento no entorno das cristas quartzíticas, formatando-se as áreas de relevo mais suavizado da bacia do Rio Verde em sua porção adstrita ao Planalto do Alto Rio Grande. Uma topografia colinosa produto de dissecação recente, de idade essencialmente quaternária, é tangenciada pelos abruptos topográficos quartzíticos sobrelevados com topos preservados da erosão remontante.

Normalmente, as grandes faixas quartzíticas definem superfícies mais elevadas, principalmente quando associadas a importantes zonas de cisalhamento. Assim também se verifica no caso da Serra da Pedra Branca, linha divisória das bacias dos rios Verde e Sapucaí e que termina em ruptura de declive no vale do Rio Lambari, que, em conjunto com a rede de drenagem da bacia, definem superfícies agradacionais em diferentes níveis altimétricos.

$\mathrm{Na}$ posição a nordeste das cristas quartzíticas da bacia do Rio Verde, na região de Cruzília e Minduri, conforma-se um compartimento planáltico que tem sua 
porção sul adstrita à área de estudo. Trata-se de uma área de topografia também caracterizada por ondulação mais suave e menores amplitudes altimétricas, se apresentando como uma superfície de erosão preservada de processos tectônicos que acometeram os compartimentos montanhosos adjacentes, afetados pelas maiores zonas de cisalhamento, e que, em função disso, teria sido atacada e nivelada pela erosão de forma mais contundente.

A Serra das Águas, localizada no município de Lambari, também pode ser considerada uma superfície de caráter estrutural. Encontra-se em condição de cimeira com proeminências acima de 1500 metros por ascenção diferencial imposta pela Zona de Cisalhamento de Lambari. Diferentemente das cristas quartzíticas, sua litologia é composta por biotita-gnaisses, similares aos que ocorrem nos compartimentos mais rebaixados, argumento que desqualifica uma correlação plausível com residuais de aplainamento dados pela resistência da rocha e advoga a favor de pulsos ascencionais preferenciais na linha cisalhante. $O$ aplainamento nos topos também é variável, configurando-se ora divisores estreitos, ora patamares planos, sobretudo na sua extremidade sudoeste contida na bacia do Rio Verde. Ainda assim, malgrado o controle tectônico, nas cimeiras da Serra das Águas podem ser encontrados LATOSSOLOS residuais. Sobre isso, Ker (1993) chama a atenção para a tendência de se estabelecer correlações entre a ocorrência de coberturas latossólicas nos topos com a Superfície Sul-americana, quadro que se verifica com maior clareza nos relevos tabuliformes do Brasil Central. Nesse caso, correlações mais taxativas só seriam cabíveis mediante a datação de tais materiais, que não chegam a apresentar espessuras significativas sugestivas de longo tempo de atividade pedogenética contínua.

Os pisos mais recentes representados pelos alvéolos que conformam as superfícies agradacionais remontam os terrenos depressionários da coalescência das planícies dos rios Sapucaí e Verde na região da represa de Furnas até a Serra da Mantiqueira, onde controles tectônicos locais geram planícies de cimeira em blocos soerguidos limitadas por frentes escarpadas e soleiras. Esses compartimentos são de idade neoquaternária, essencialmente holocênicos.

Em face às discussões colocadas em tela, reconhece-se a presença de três níveis de base de maior ordem de grandeza na bacia do Rio Verde definidores da 
compartimentação mais geral do relevo: 1. Contato entre as cristas principais da Mantiqueira com os compartimentos interiores, entre 1000 e 1200 metros, intervalo altimétrico no qual os principais rios da bacia transpõem os alinhamentos e as intrusões alcalinas, formando-se as primeiras planícies aluviais e definindo dois níveis planálticos gerais para a Serra da Mantiqueira;

2. Contato entre a Serra da Mantiqueira e Planalto do Alto Rio Grande em faixas de 900 a 1000 metros de altitude (fundos de vale). Coincide com o início do desenvolvimento de planícies de inundação mais contínuas e com as principais confluências de alto curso.

3. Área de influência da Represa de Furnas, em faixas de 800 metros de elevação. Posiciona-se na passagem para o Planalto de Varginha.

Níveis de base locais, como soleiras que se formam em vales altimontanos, também exercem influência marcante na compartimentação do relevo em escala mais detalhada. Assim se verifica nos vales sobrelevados dos rios Santo Agostinho e São Pedro em Baependi, ou formadores do Rio Capivari em Itamonte. Vales estruturais distais às cristas quartzíticas também configuram níveis de base de maior ordem em compartimento submetido aos níveis mais abrangentes.

Em síntese, embora seja admissível a existência de níveis mais antigos em patamares de cimeira preservados, admite-se também o forte controle litoestrutural vigente nesse setor da Plataforma Brasileira, que desnivela superfícies de mesma geração e coloca no mesmo plano altimétrico níveis de geração distinta, limitando fortemente a aplicação exclusiva do critério altimétrico na interpretação das superfícies geomorfológicas. Da maneira que foi mencionado, para a área de estudo é possível reconhecer superfícies mais antigas preservadas por resistência desigual da rocha (cristas quartzíticas, intrusões alcalinas), bem como superfícies mais recentes soerguidas a níveis mais elevados.

O caráter tectônico de alguns compartimentos do relevo, assinaladamente na Serra da Mantiqueira, é elemento complicador para a interpretação das superfícies geomórficas, deixando questões um tanto nebulosas a respeito da quantidade de níveis existentes e quais são aqueles correlacionáveis cronologicamente. No entanto, a região do Sul de Minas, da qual a bacia do Rio Verde é fortemente representativa, possui fatalmente diferentes níveis topográficos 
AS SUPERFÍCIES GEOMORFOLÓGICAS E A EVOLUÇÃO DO RELEVO BRASILEIRO: TRANSCURSO DAS IDEIAS E CORRESPONDÊNCIAS NO SUL DE MINAS GERAIS, SUDESTE DO BRASIL)

decorrentes de fases diferentes de aplainamento, sobrepondo-se morfologias ligadas ao controle climático, rebaixadas e arredondadas, e compartimentos tectonicamente controlados, deformados e desnivelados por processos de arqueamento e basculamento. Essa interferência de fatores erosivos e tectônicos se ajusta aos estudos empreendidos para os terrenos cristalinos do Brasil Oriental que foram discutidos.

Em caráter suplementar às interpretações discutidas, foi associada por somatória a área total dos topos preservados nos sistemas de relevo mais elevados, que guardam alguma relação morfológica com superfícies mais antigas. A leitura do quadro 1 fornece uma visão conjunta da representatividade areolar dos topos e de sua posição altimétrica.

\begin{tabular}{|c|c|c|c|l|}
\hline $\begin{array}{c}\text { ALTIMETRIA } \\
\text { (metros) }\end{array}$ & $\begin{array}{c}\text { SOMA DAS } \\
\text { ÁREAS } \text { (m }^{2} \text { ) }\end{array}$ & $\begin{array}{c}\text { \% DA ÁREA } \\
\text { TOTAL DOS } \\
\text { TOPOS }\end{array}$ & $\begin{array}{c}\text { \% DA ÁREA } \\
\text { TOTAL DA } \\
\text { BACIA }\end{array}$ & $\begin{array}{c}\text { PRINCIPAIS FORMAS DE } \\
\text { RELEVO ASSOCIADAS }\end{array}$ \\
\hline$>2000$ & 6.213 & $1,5 \%$ & $0,09 \%$ & $\begin{array}{l}\text { Maciços alcalinos, altas cristas } \\
\text { da Mantiqueira. }\end{array}$ \\
\hline $1500-2000$ & 59.634 & $14,6 \%$ & $0,86 \%$ & $\begin{array}{l}\text { Cristas paralelas, serras } \\
\text { alongadas elevadas, morros } \\
\text { profundamente dissecados. }\end{array}$ \\
\hline $1200-1500$ & $86.646,5$ & $20,7 \%$ & $1,26 \%$ & $\begin{array}{l}\text { Cristas paralelas, serras baixas, } \\
\text { morros e morrotes. }\end{array}$ \\
\hline$<1200$ & 228.005 & $63,2 \%$ & $3,22 \%$ & $\begin{array}{l}\text { Serras baixas, morros, morrotes } \\
\text { e colinas. }\end{array}$ \\
\hline
\end{tabular}

Quadro 1: Distribuição altimétrica dos topos na bacia do Rio Verde (MG).

No total, a área dos topos corresponde a aproximadamente 5,5\% da área da bacia, apresentando maior continuidade na Serra da Mantiqueira e ao longo das cristas monoclinais do Planalto do Alto Rio Grande.

Apenas uma pequena parte equivalente a 1,5\% encontra-se acima de 2000 metros, correspondendo à porção dos maciços alcalinos de Itatiaia e Passa Quatro pertencentes às terras drenadas pela bacia do Rio Verde e às proeminências localizadas nas cumeadas da Serra do Papagaio, em Baependi e Aiuruoca. As altitudes máximas têm, portanto, uma forte gênese estrutural, e preservam superfícies geomorfológicas de destaque. É provável que os patamares acima de 1500 metros, e mesmo alguns rebaixados até a faixa dos 1200 metros correspondam à mesma superfície tectonicamente deformada. As faixas acima de 
1500 metros ocorrem quase que exclusivamente na Serra da Mantiqueira, agrupando-se em compartimentos escalonados que perfazem tanto patamares de cimeira extensos e contínuos como o da Pedra Branca, que aponta acima de 1800 metros, como pequenos topos aguçados a arredondados pelas serranias de Virgínia e adjacências. Entre 1200 e 1500 metros se adéquam os topos mais baixos da Mantiqueira, a oeste das cristas principais, e os níveis de cimeira do Planalto do Alto Rio Grande, conforme ocorre nas cristas monoclinais da região de São Thomé das Letras e Lambari. Abaixo de 1200 metros estão os topos dos morros e colinas, além de alguns alinhamentos serranos mais rebaixados, que se tipificam em topografia ondulada e convexa em vários compartimentos do planalto do Alto Rio Grande, e mesmo pelos degraus escalonados da Mantiqueira.

A figura 2 consiste numa representação cartográfica dos topos mapeáveis em escala de 1/250.000. Embora o nível de detalhe não permita uma representação de todos os topos calculados, é capaz de fornecer uma visualização espacial da distribuição dos mesmos segundo sua altimetria.

Notoriamente, como revela a figura, as cimeiras regionais correspondem a relevos essencialmente tectônicos. Notadamente, os níveis mais elevados estão no Planalto do Itatiaia, lócus das manifestações intrusivas alcalinas; na porção compreendida no Planalto de Campos do Jordão, quando a linha divisória da bacia troca a orientação NE-SW para NW-SE, nenhuma cota altimétrica ultrapassa 2000 metros de altitude. Ainda assim, é na Serra da Mantiqueira onde estão as faixas altimétricas mais elevadas, concentradas principalmente nas cristas principais. Pelos patamares escalonados que incidem em direção aos planaltos do alto Rio Grande, as cotas mais baixas denotam o desnivelamento tectônico dessa superfície, que fica evidente com a abrupta queda altimétrica entre os topos das cristas principais e as cimeiras dos compartimentos abatidos. 


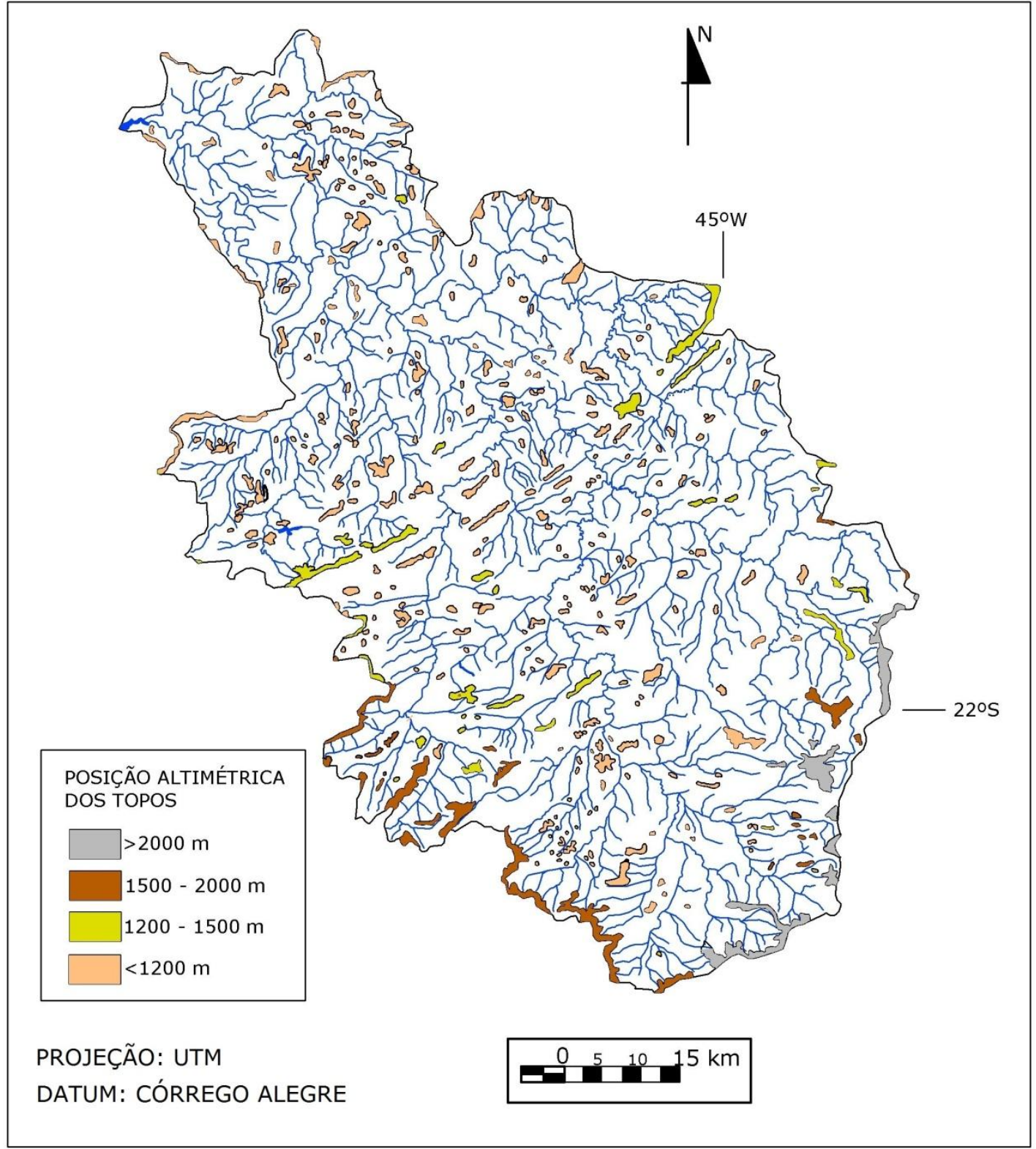

Figura 2: Distribuição altimétrica dos topos e altas encostas na bacia do Rio Verde.

Um notório alinhamento dos topos é também revelador do controle tectônico, às vezes correspondendo a importantes zonas de cisalhamento como a de São Bento do Sapucaí e Maria da Fé bem marcada na porção sudoeste da bacia, por onde adentram a partir da bacia do Rio Sapucaí. No Planalto do Alto Rio Grande tais alinhamentos são proemimentes ao longo das cristas monoclinais que atravessam a parte média da bacia, bem como em faixas orográficas mais rebaixadas que acompanham linhas de drenagem estruturalmente adaptadas. Dessa forma, as maiores elevações estão vinculadas às principais descontinuidades crustais da bacia 
ou a massas intrusivas como as de Itatiaia e Passa Quatro e, em menor medida, do bloco granulítico de Cristina. Fatores estruturais marcantes, como a resistência dos quartzitos e sienitos, advogam a favor da inserção de processos de erosão diferencial que atacaram com maior rigor as litologias granitoides. Conforme fora colocado, perfis bauxíticos marcando superfícies geomorfológicas também podem ser encontrados.

Abaixo de 1200 metros os topos perdem seu aspecto aguçado e se encontram mais suavizados. As serras mais rebaixadas tendem a convexação de suas formas, e o arredondamento se distribui em morros e pequenas colinas. Nessas áreas de maior desgaste químico é que os mantos de alteração estiveram sendo formados e removidos, subnivelando formas mamelonares interceptadas por relevos de estrutura falhada. Algumas superfícies mais antigas encontram-se provavelmente preservadas nesses compartimentos rebaixados em perfis lateríticos, mostrando a ocorrência de perfis de intemperismo desta estirpe em diversas faixas altimétricas.

\section{CONCLUSÕES}

Alguns pontos conclusivos podem ser enumerados a partir das discussões arroladas no presente artigo, os quais seguem elencados:

1. O entendimento da evolução do relevo brasileiro a partir das superfícies geomorfológicas de expressão regional é tarefa difícil e de pouco consenso; ainda assim, diferentes níveis topográficos permitem correlações regionais de grande valia para estudos acerca da evolução morfológica de uma dada área;

2. Entre a plêiade de nomenclaturas e relações temporais propugnadas pelos autores que se dedicaram ao tema, indubitavelmente a Superfície Sulamericana configura a principal coadunação de ideias a esse respeito no que se refere à idade de elaboração e posicionamento na paisagem;

3. As correlações entre tais níveis não deve se valer exclusivamente do critério altimétrico, uma vez que fatores estruturais e tectônicos atuam na preservação e desnivelamento de superfícies cronocorrelatas, bem como na aproximação altimétrica de superfícies de geração distintas, limitando o alcance das análises morfométricas para estudos de tal ordem; 
AS SUPERFÍCIES GEOMORFOLÓGICAS E A EVOLUÇÃO DO RELEVO BRASILEIRO: TRANSCURSO DAS IDEIAS E CORRESPONDÊNCIAS NO SUL DE MINAS GERAIS, SUDESTE DO BRASIL)

4. A limitação dos registros na forma de perfis bauxíticos e lateríticos, bem como a escassez de dados concernentes a idade absoluta dos registros existentes, dificulta as correlações regionais;

5. A atuação conjunta de fatores climáticos, tectônicos e estruturais encerra grande complexidade no estudo da evolução do relevo por meio das superfícies geomorfológicas; mesmo assim, estas configuram importante referência para a compartimentação regional do relevo e para a investigação de sua evolução.

\section{REFERÊNCIAS}

AB'SÁBER, A.N. Posição das Superfícies Aplainadas no Planalto Brasileiro. Notícia Geomorfológica. v. 3, n. 5. Campinas, 1960.

Participação das Superfícies Aplainadas nas Paisagens do Nordeste Brasileiro. Geomorfologia. n. 19. São Paulo, 1969.

Geomorfologia do sítio urbano de São Paulo. Cotia, SP: Ateliê Editorial, 349p. 2007.

; BIGARELLA, J.J. Superfícies Aplainadas no Primeiro Planalto do Paraná. Boletim Paranaense de Geografia. n. 4/5. p. 117-125, 1961.

ALMEIDA, F.F.M. Relevos policíclicos no Planalto Brasileiro. Boletim Paulista de Geografia, n. 7, p. 1-19, 1951.

Geologia do Estado de São Paulo. Boletim n 41, 263p.

1964.

; CARNEIRO, C.D.R. Origem e evolução da Serra do Mar. Revista Brasileira de Geociências, São Paulo, v. 28, n. 2, 1998.

BARBOSA, G.V. Identificação de superfícies de erosão por imagem de radar na parte oriental da Bahia. In: XXIX CONGRESSO BRASILEIRO DE GEOLOGIA. Anais... Ouro Preto, p. 237-249, 1976.

Superfícies de Erosão no Quadrilátero Ferrífero, Minas Gerais. Revista Brasileira de Geociências. São Paulo, v. 10, p. 89-101, 1980.

BIGARELLA, J.J. Estrutura e origem das paisagens tropicais de subtropicais. v. 3. Florianópolis: ed. da UFSC, 2003. 
AS SUPERFÍCIES GEOMORFOLÓGICAS E A EVOLUÇÃO DO RELEVO BRASILEIRO: TRANSCURSO DAS IDEIAS E CORRESPONDÊNCIAS NO SUL DE MINAS GERAIS, SUDESTE DO BRASIL)

; MOUSINHO, M.R. Considerações a respeito dos terraços, rampas de colúvio e várzeas. Boletim Paranaense de Geografia. Curitiba, n. 16/17, p. 153-198, 1965.

BRAUN, O.P.G. Contribuição à Geomorfologia do Brasil Central. Revista Brasileira de Geografia. 32(3). 3-39, 1971.

CLARKE, J.I. Morphometry from maps. In: DURY, G.H. (Ed.) Essays in geomorphology. New York: Elsevier, 1966.

COSTA, M.L. Aspectos geológicos dos lateritos da Amazônia. Revista Brasileira de Geociências, v. 21, n. 2, p. 146-160, 1991.

DANIELS, R.B.; HAMMER, R.D. Soil geomorphology. New York: Wiley e Sons, inc. 1992.

DE MARTONNE, E. Problemas morfológicos do Brasil Tropical Atlântico. Revista Brasileira de Geografia, v. 5, n. 4, p. 532-550, 1943.

FREITAS, R.O. Ensaio sobre a tectônica moderna do Brasil. Geologia, São Paulo, n. 6, 119p. 1951.

GEYL, W.F. Morphometric analysis and the world wide occurence of stripped erosion surfaces. Journal of Geology, n. 69, p. 388-416, 1961.

GONTIJO, A.H.F; BORGES, M.S.; JIMENEZ-RUEDA, J.R.; COSTA, J.B.S.; HASUI, Y.; MORALES, N. Perfis lateríticos-bauxíticos e a degradação da Superfície SulAmericana: um exemplo na Serra da Bocaina, estados de São Paulo e Rio de Janeiro. Geociências, São Paulo, UNESP, v. 21, n. 1/2, p. 5-13, 2002.

HARTWIG, M.E. Tectônica rúptil mesozóico-cenozóica na região da Serra dos Órgãos, RJ. São Paulo, 117f. Dissertação (mestrado em Geoquímica e Geotectônica), Instituto de Geociências, Universidade de São Paulo, São Paulo, 2006.

HIRUMA, S.T. Significado morfotectônico dos planaltos isolados da Bocaina. Tese (Doutorado em Geoquímica e Geotectônica). Instituto de Geociências, Universidade de São Paulo. São Paulo, 2007.

INSTITUTO BRASILEIRO DE GEOGRAFIA E ESTATíSTICA. Folha Volta Redonda, SF-23-Z-A (1 ${ }^{\circ}$ edição), 1976. 
AS SUPERFÍCIES GEOMORFOLÓGICAS E A EVOLUÇÃO DO RELEVO BRASILEIRO: TRANSCURSO DAS IDEIAS E CORRESPONDÊNCIAS NO SUL DE MINAS GERAIS, SUDESTE DO BRASIL)

Folha Barbacena,

SF-23-X-C (1 edição), 1979.

Folha Varginha,

SF-23-V-D (2 edição), 1979.

Folha

Guaratinguetá, SF-23-Y-B (reimpressão), 1985.

JAMES, P. The surface configuration of southeastern Brazil. Annals of Association American Geography. v. 33, n. 3, p. 165-193, 1933.

KER, J.C. Latossolos do Brasil: uma revisão. Geonomos, v. 7, n. 1, p. 17-40

KING, L.C.A Geomorfologia do Brasil Oriental. Revista Brasileira de Geografia. Rio de Janeiro, 18: 147-265, 1956.

The Morphology of the Earth. Edinburgh: Olier e Boyd, 699p.

1962.

Planation remnants upon high lands. Z. Geomorphologie. v. 20, n. 2, p. 133-148, 1976.

LADEIRA, F.S.B.; SANTOS, M. Uso de paleossolos e perfis de alteração para a identificação e análise de superfícies geomórficas regionais: o caso da Serra de Itaqueri (SP). Revista Brasileira de Geomorfologia. Ano 6, n. 2, p. 3-20, 2005.

LIU, C.C. Análise estrutural de lineamentos em imagens de sensoriamento remoto: aplicações ao estado do Rio de Janeiro. São Paulo, Tese (Doutorado em Geologia). Instituto de Geociências, Universidade de São Paulo. 1984.

MAGALHÃES JR. A.; TRINDADE, E.S. Relações entre níveis (paleo) topográficos e domínios morfotectônicos na região Sul de Minas Gerais: contribuição ao estudo das superfícies erosivas no sudeste brasileiro. Revista Brasileira de Geomorfologia, ano 5, n. 1, p. 01-10, 2004.

MARQUES NETO, R. Estudo evolutivo do sistema morfoclimático e morfotectônico da bacia do Rio Verde (MG), sudeste do Brasil. 2012, 429p. Tese (Doutorado em Geografia), Instituto de Geociências e Ciências Exatas, Universidade Estadual Paulista. Rio Claro, 2012. 
AS SUPERFÍCIES GEOMORFOLÓGICAS E A EVOLUÇÃO DO RELEVO BRASILEIRO: TRANSCURSO DAS IDEIAS E CORRESPONDÊNCIAS NO SUL DE MINAS GERAIS, SUDESTE DO BRASIL)

MOTTA, P.E.F; CARVALHO FILHO, A.; KER, J.C.; PEREIRA, N.R.; CARVALHO JR. W.; BLANCANEAUX, P. Relações solo-superfície geomórfica e evolução da paisagem em uma área do Planalto Central Brasileiro. Pesquisa Agropecuária Brasileira, Brasília, v. 37, n. 6, p. 869-878, 2002.

NASCIMENTO, M.A.L.S. Geomorfologia do estado de Goiás. Boletim Goiano de Geografia. Goiânia, v. 12, n.1, p. 1-22, 1992.

PAISANI, J.C.; PONTELLI, M.E.; ANDRES, J. Superfícies aplainadas em zona morfoclimática subtropical úmida no planalto basáltico da Bacia do Paraná (SW Paraná/NW Santa Catarina): primeira aproximação. Geociências, São Paulo, UNESP, v. 27, n. 4, p. 541-553, 2008.

PENTEADO, M.M. Implicações tectônicas na gênese das cuestas basálticas de Rio Claro. Notícia Geomorfológica, Campinas, v. 8, n. 15, p. 19-41, 1968.

PEUVAST, J.P.; SALES, V.C. Aplainamento e geodinâmica: revisitando um problema clássico em geomorfologia. Mercator, Fortaleza, UFC, ano 1, n. 1, p. 113150, 2002.

PINTO, M.N. Residuais de aplainamentos na "chapada" dos Veadeiros - Goiás. Revista Brasileira de Geografia, Rio de Janeiro, v. 48, n. 2, p. 187-197, 1986.

Aplainamento nos Trópicos: uma Revisão Conceitual. Geografia. Rio Claro, v. 13, n. 26, p. 119-129, 1988.

RANZANI, G.; PENTEADO, M.M.; SILVEIRA, J.D. Concreções ferruginosas, paleossolos e a superfície de cimeira no Planalto Ocidental Paulista. Geomorfologia, São Paulo, n. 31, 28p. 1972.

RICCOMINI, C.; SANT'ANNA, L.G.; FERRARI, A.L. Evolução geológica do Rift Continental do Sudeste do Brasil. In: MANTESSO-NETO, V.; BATORELLI, A.; CARNEIRO, C.D.R.; BRITO-NEVES, B.B. (Ed.). Geologia do continente SulAmericano: evolução da obra de Fernando Flávio Marques de Almeida. São Paulo: Beca, p. 383-405. 2004.

ROMANO, A.W.; CASTAÑEDA, C. A tectônica distensiva pós-mesozóica no condicionamento dos depósitos de bauxita da Zona da Mata Mineira. Geonomos, v. 14, n. 1/2, p. 1-5, 2006.

SCHOBBENHAUS, C.; CAMPOS, D.A.; DERZE, G.R.; ASMUS, H.E. Geologia do Brasil. Brasília: MME/DNPM, 501p. 1984. 
AS SUPERFÍCIES GEOMORFOLÓGICAS E A EVOLUÇÃO DO RELEVO BRASILEIRO: TRANSCURSO DAS IDEIAS E CORRESPONDÊNCIAS NO SUL DE MINAS GERAIS, SUDESTE DO BRASIL)

SÍGOLO, J.B. Os depósitos de talude de Passa Quatro. In: V SIMPÓSIO DE GEOLOGIA DO SUDESTE, Anais... Penedo, RJ, v. 1, p. 1-8. 1997.

SILVA, T.M. Superfícies geomorfológicas no Planalto Sudeste Brasileiro: revisão teórico-conceitual. Geo UERJ, Rio de Janeiro, v. 3, n. 20, p. 1-22, 2009.

SMALL, R.J. The study of planation surfaces. In: The study of landforms: a textbook of Geomorphology. Cambridge: University Press, p. 248-272, 1986.

THOMAS, M. Geomorphology in the tropics: a study of eathering and denudation in low latitudes. New York: John Wiley e Sons, 460p. 1994.

VALADÃO, R.C. Evolução de Iongo termo do relevo do Brasil Oriental: desnudação, superfície de aplainamento e movimentos crustais. Salvador, 423p. Tese de Doutorado, Instituto de Geociências, Universidade Federal da Bahia. 1998.

Geodinâmica de superfícies de aplainamento, desnudação continental e tectônica ativa como condicionantes da megageomorfologia do Brasil Oriental. Revista Brasileira de Geomorfologia. Uberlândia, v. 10, n. 2, p. 77-90, 2009.

VALETON, I.; MELFI, A.J. Distribution pattern of bauxites in Cataguases area (SE Brazil), in relation to Lower Terciary paleogeographic and younger tectonics. Bulletin de la Societé Géologique de France, v. 41, n.1, p. 85-98, 1988.

VARAJÃO, C.A.C.A questão da correlação das superfícies de erosão do Quadrilátero Ferrífero, Minas Gerais. Revista Brasileira de Geociências. São Paulo, v. 21, n. 2, p. 138-145, 1991.

WASHBURNE, C. Petroleum geology of the State of São Paulo, Brasil. Comissão Geográfica e Geológica Brasileira. Boletim n. 22, 1930.

ZALAN, P.V.; OLIVEIRA, J.A.B. Origem e evolução estrutural do Sistema de Riftes Cenozóicos do Sudeste do Brasil. Boletim de Geociências da Petrobrás, Rio de Janeiro, v. 13, n. 2, p. 269-300, 2005. 